九州大学学術情報リポジトリ

Kyushu University Institutional Repository

\title{
Water Quality Conservation in an Agricultural Pond using an Ecosystem Model and Scenario Analys is
}

Ix, Hour

Graduate School of Bioresource and Bioenvironmental Sciences, Kyushu University

Hiramatsu, Kazuaki

Faculty of Agriculture, Kyushu University

Harada, Masayoshi

Faculty of Agriculture, Kyushu University

Mori, Makito

Faculty of Agriculture, Kyushu University

https://doi.org/10.5109/9332

出版情報: 九州大学大学院農学研究院紀要. 52 (2)，pp.423-429，2007-10-29. Faculty of Agriculture, Kyushu University

バージョン :

権利関係 : 


\title{
Water Quality Conservation in an Agricultural Pond using an Ecosystem Model and Scenario Analysis
}

\author{
Hour IX ${ }^{1 *}$, Kazuaki HIRAMATSU, Masayoshi HARADA \\ and Makito MORI
}

\author{
Laboratory of Drainage and Water Environment, Division of Regional Environment Science, \\ Department of Bioproduction Environmental Sciences, Faculty of Agriculture, \\ Kyushu University, Fukuoka 812-8581, Japan \\ (Received May 16, 2007 and accepted July 17, 2007)
}

\begin{abstract}
To explicate the dynamics of nitrogen and phosphorus in an agricultural pond, numerical simulations were conducted for their temporal fluctuation in pond water by using an ecosystem model, and the developed model was applied to a scenario analysis for the improvement and preservation of water environment by the reduction of nitrogen and phosphorus. In this study, the model was composed of 5 water quality indices-nitrogen oxides, ammonia-nitrogen, organic nitrogen, phosphate-phosphorus and organic phosphorus-and was adapted to the Toishigawara agricultural pond in Fukuoka Prefecture, Japan, where concentrations of total nitrogen and total phosphorous were extraordinarily high. A comparison between the calculated results and the observed data showed that the ecosystem model used in this study could reproduce the dynamics of nitrogen and phosphorus in Toishigawara pond. According to the scenario analysis, $80 \%$ reduction of current nutrient inflow load resulted in the remarkable decrease of total nitrogen and total phosphorous concentrations. As a result, total nitrogen fulfilled the water quality standard of irrigation water in Japan.
\end{abstract}

\section{INTRODUCTION}

Water quality has increasingly become a crucial issue for researchers and scientists in their studies (Kato, 2005(a); 2005(b)). Total nitrogen and total phosphorus are the most important water quality indices to be studied for the water quality conservation issue. Overloading of either nitrogen or phosphorus will result in an eutrophication condition which promotes more plant growth and decay, increasing biochemical oxygen demand in water body (Zheng et al., 2004). This is the critical issue of water pollution as the plant growth and respiration can affect the system's water chemistry, most notably oxygen and carbon dioxide (Chapra, 1997). Eventually there will be serious negative effects when such polluted water is later utilized as irrigation water for agricultural land (Schwarz et al., 2005).

The eutrophication is due to excessive nutrients of nitrogen and phosphorus caused by human activities (Chapra, 1997; Cheng et al., 2006). Moreover, the shallow factor has considerably contributed to the eutrophication condition (Qin et al., 2006). In addition, because warm water increased the rate of many chemical reactions occurring in the pond, it was possible to dissolve more substances (Davie, 2002; Chapra, 1997). Therefore, nutrient cycles for nitrogen and phosphorous in water need to be quantitatively evaluated to improve and preserve the eutrophic water body, and the numeri-

1 Laboratory of Drainage and Water Environment, Division of Regional Environment Science, Department of Bioproduction Environmental Sciences, Graduate School of Bioresource and Bioenvironmental Sciences, Kyushu University, Fukuoka 812-8581, Japan

* Corresponding author (E-mail: hourix2005@yahoo.com) cal simulation is the most effective approach for the assessment of water environment dynamic.

In this study, an ecosystem model is constructed as the predictive model for the dynamics of water quality indices of nitrogen and phosphorous, and is then applied to the environmental assessment of an eutrophic agricultural pond. The ecosystem model is a water quality model into which the biochemical and ecological processes in the nutrient cycle can be incorporated. The ecosystem model adopted in this study is the simplest and most basic model composed of 5 water quality indices-nitrogen oxides $\left(\mathrm{NO}_{\mathrm{x}}-\mathrm{N}\right)$, ammonia-nitrogen $\left(\mathrm{NH}_{4}-\mathrm{N}\right)$, organic nitrogen $(\mathrm{Org}-\mathrm{N})$, phosphate-phosphorus $\left(\mathrm{PO}_{4}-\mathrm{P}\right)$ and organic phosphorus (Org-P).

The objective agricultural pond is the Toishigawara agricultural pond located in Sasaguri Town in Fukuoka Prefecture, Japan. According to the observation by Saitoh et al. (2006), concentrations of both the total nitrogen (TN) and total phosphorous (TP) were extraordinarily high. Especially, TN concentration was considerably beyond Japanese water quality standard of irrigation water for the paddy rice cultivation. In this study, the effectiveness and validity of this model is first verified by comparison between the observed and the simulated results. Subsequently, the scenario analysis is conducted for the reduction of nitrogen and phosphorous in pond water to improve or prevent the eutrophication.

\section{DATA AND METHODOLOGIES}

\section{Study Area}

Analyses of water quality indices in an eutrophic agricultural pond by using an ecosystem model are carried out on Toishigawara pond located in Sasaguri Town 
in Fukuoka Prefecture, Japan. This pond could provide irrigation water to the surrounding agricultural land. Being located in a relatively flat and low area, Toishigawara pond receives inflow water from the high-elevated forest, as well as settlement areas adjacent to it (see Fig. 1). The pond has a total storage capacity of approximately $2,200 \mathrm{~m}^{3}$ of water, a surface area of about $840 \mathrm{~m}^{2}$, and a periphery of around $140 \mathrm{~m}$. Judging from an average depth of about $2 \mathrm{~m}$, the pond is regarded as a rather shallow water body. Toishigawara pond is an eutrophic lake where a large amount of phytoplankton such as blue-green algae has overgrown in summer for the past several years.

\section{Data Used}

Data used in this research are classified into three different types: natural characteristics of the pond, observed water quality data, and meteorological data.

Natural characteristic data consists of water volume and surface area of the pond. These data are significantly important for numerical calculation to predict the fluctuating accumulation of water quality indices of TN and TP. Meanwhile, observed water quality data used in this study are obtained from 2 different sources: pond water and inflow water. The observed period used for this ecosystem modeling was from July 4th to September 20th. Finally, meteorological data provides important information for determining the biochemical, ecological and physical processes in the ecosystem model. Especially, daily rainfall data are unavoidably required in the ecosystem model adapted in this study.

\section{Methodologies}

In this research, water sampling was conducted as a tool of measuring water quality indices. With this methodology, sample waters were analyzed in the laboratory to determine the variation of total nitrogen and phosphorus in 5 different formations: $\mathrm{NOx}-\mathrm{N}, \mathrm{NH}_{4}-\mathrm{N}$, Org-N, $\mathrm{PO}_{4}-\mathrm{N}$ and Org-P. The results acquired from water sampling were then used as a tool to determine the effectiveness and accuracy of the mathematical model.

\subsection{Water Sampling Process}

A weekly water sampling process was conducted to specify the level of pollution and fluctuating concentrations of nitrogen and phosphorus in both pond and inflow. Samples were retrieved once a week directly

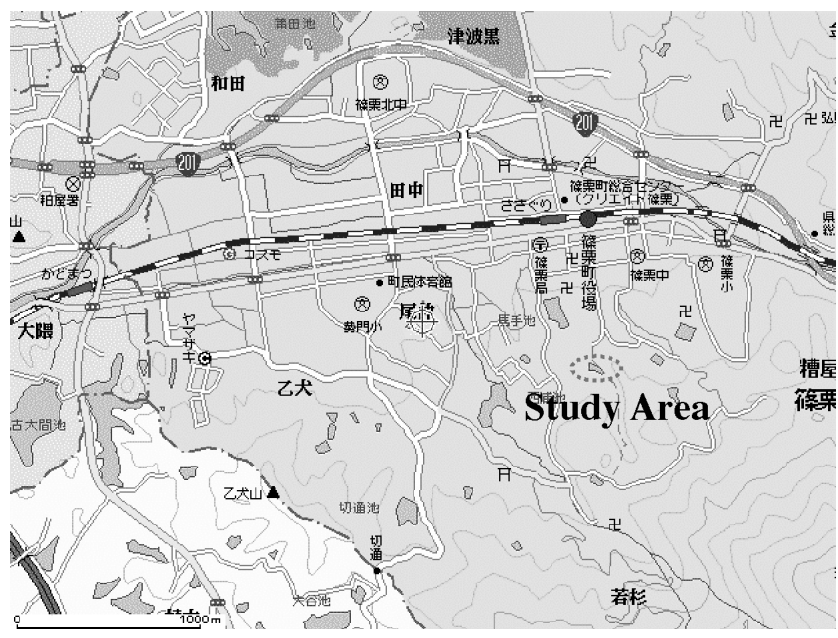

(a) Study area (Toishigawara agricultural pond)

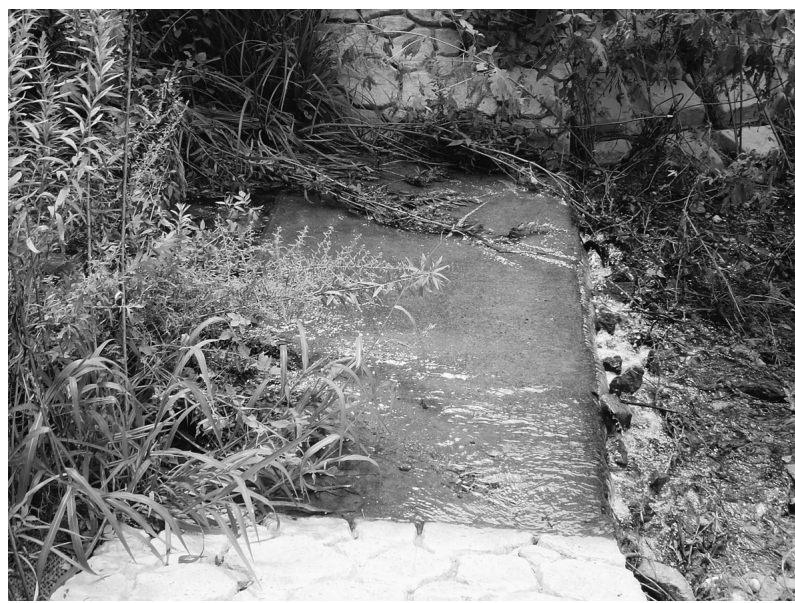

(b) River inflow

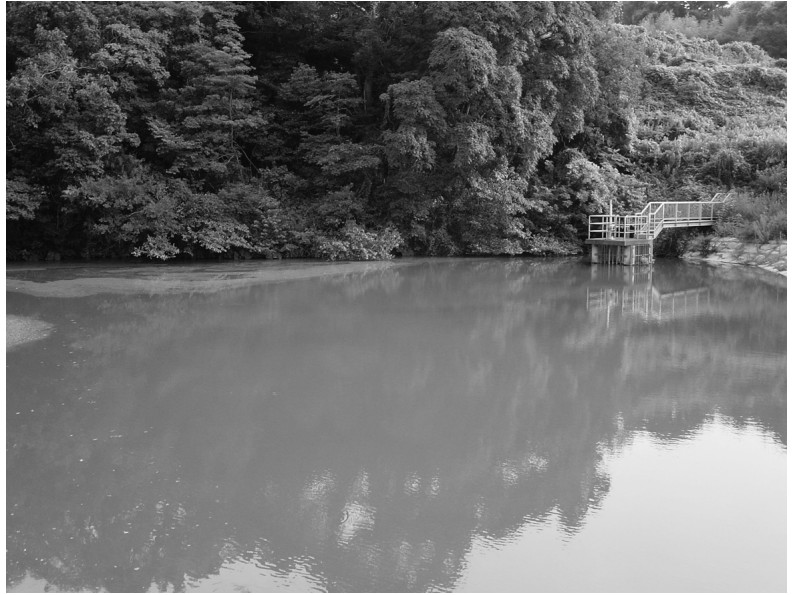

(c) Pond body

Fig. 1. Location of Toishigawara agricultural pond. 
from the field and taken to the laboratory to analyze the concentrations of $\mathrm{NO}_{3}-\mathrm{N}, \mathrm{NO}_{2}-\mathrm{N}, \mathrm{NH}_{4}-\mathrm{N}, \mathrm{PO}_{4}-\mathrm{P}, \mathrm{TN}, \mathrm{TP}$, chlorophyll-a and COD. Concentrations of organic nitrogen (Org-N) and organic phosphorus (Org-P) were determined by subtracting inorganic ion formations from the total amount. The observed results are shown in Fig. 2.

Dissolved oxygen, water temperature, $\mathrm{pH}$, electric conductivity and transparency were also measured on site.

Furthermore, meteorological elements such as wind speed, air temperature, humidity and rainfall were continuously recorded at an interval of ten minutes by data logger. The discharge of inflow into the pond was measured in parallel with sampling water. As the water level of the pond remains constant, the amount of outflow water could be evaluated as the summation of inflow and rainfall volume running into the pond.

\subsection{Ecosystem Model}

An ecosystem model was developed for predicting the daily variation of nitrogen $(\mathrm{N})$ and phosphorus $(\mathrm{P})$ in Toishigawara pond. In the modeling, the interactions among the five water quality indices of nitrogen oxides $\left(\mathrm{NO}_{\mathrm{x}}-\mathrm{N}\right)$, ammonia-nitrogen $\left(\mathrm{NH}_{4}-\mathrm{N}\right)$, organic nitrogen (Org-N), phosphate-phosphorus $\left(\mathrm{PO}_{4}-\mathrm{P}\right)$ and organic phosphorus (Org-P) are described by first-order kinetics. Org-N and Org-P consist of abiotic organism and phytoplankton (Chapra, 1997; Wetzel, 2001) as shown in Fig. 3.

Descriptions of variables in formulation of the ecosystem model are as follows.

$N$ is a concentration of nitrate-nitrogen and nitrite-nitrogen, $\mathrm{NO}_{\mathrm{x}}-\mathrm{N}$.
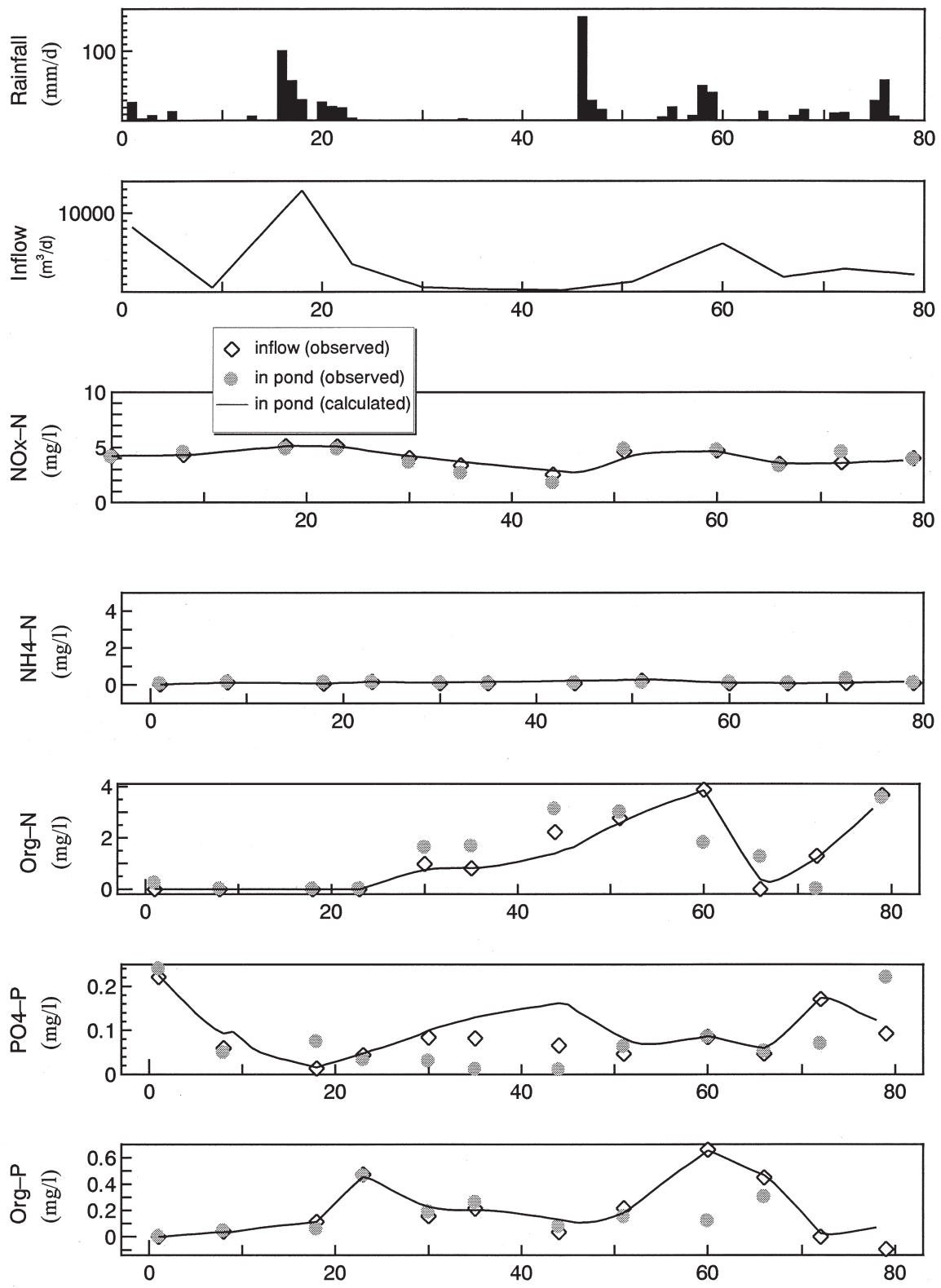

Time (d)

Fig. 2. Observed and calculated results in Toishigawara agricultural pond. 


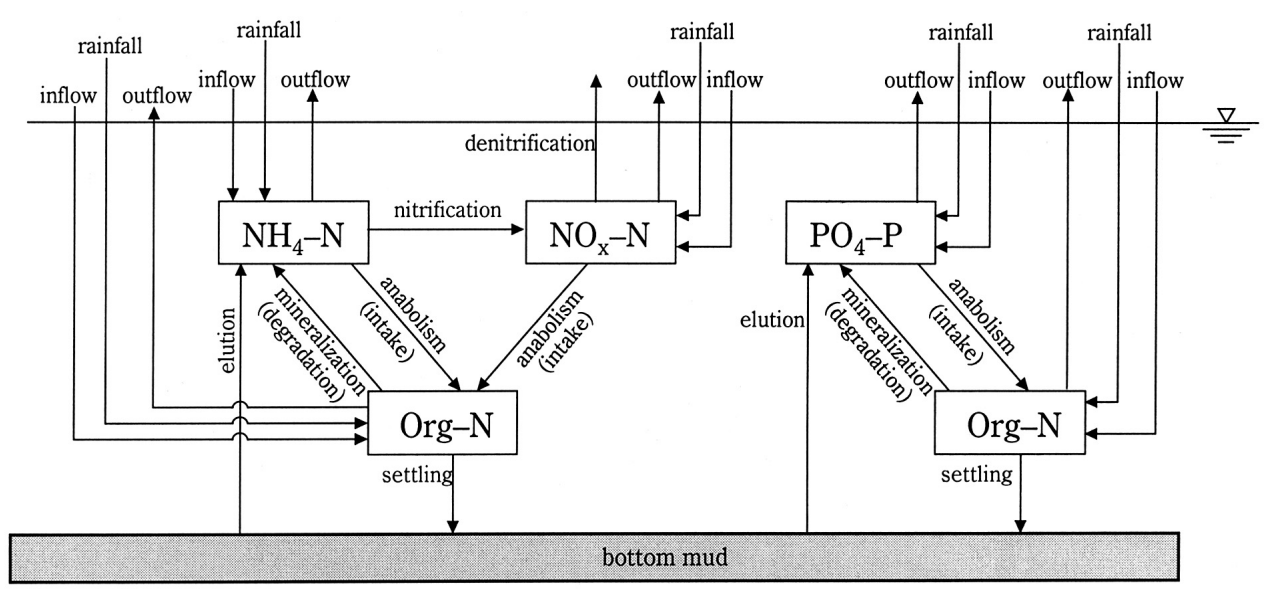

Fig. 3. Ecosystem model of Toishigawara agricultural pond.

$H$ is a concentration of ammonia-nitrogen, $\mathrm{NH}_{4}-\mathrm{N}$.

$O$ is a concentration of organic nitrogen, Org-N.

$P$ is a concentration of phosphate-phosphorus, $\mathrm{PO}_{4}-\mathrm{N}$.

$Y$ is a concentration of organic phosphorus, Org-P.

$V$ is a volume of the pond.

$A$ is an area of the pond bottom.

$h$ is a water depth defined as $h \equiv V / A$.

$q$ is a discharge running into or out of the pond.

Subscripts of "in", "R", "out" denote inflow, rainfall and outflow, respectively.

\section{Kinetics for $\mathrm{NO}_{\mathrm{X}}-\mathrm{N}\left(\mathrm{NO}_{3}-\mathrm{N}\right.$ and $\left.\mathrm{NO}_{2}-\mathrm{N}\right)(\mathrm{N})$}

Variation of $\mathrm{NO}_{\mathrm{x}}-\mathrm{N}$ per unit volume and unit time is accumulating via inflow source to the inner side of the pond, influx of $\mathrm{NO}_{\mathrm{x}}-\mathrm{N}$ itself by rainfall, and through the nitrification process of $\mathrm{NH}_{4}-\mathrm{N}$. Meanwhile, some concentration of $\mathrm{NO}_{\mathrm{x}}-\mathrm{N}$ is lost through outflow from the pond body, and through intake of nitrogen during phytoplankton, as well as the denitrification process.

$$
\frac{d N}{d t}=\frac{q_{\text {in }}}{V} N_{\text {in }}+\frac{q_{R}}{V} N_{R}-\frac{q_{\text {out }}}{V} N+\mathbf{a}_{N} H-r_{1} \mu_{N} O-\mathbf{a}_{D} \frac{N}{h}(1)
$$

where $\mathbf{a}_{N}$ is the nitrification rate $\left[\mathrm{d}^{-1}\right], \mu_{N}$ is the intake rate of $N$ by phytoplankton $\left[\mathrm{d}^{-1}\right], r_{1}$ is distribution constant to $\mathrm{NO}_{\mathrm{X}}-\mathrm{N}$ and $\mathrm{NH}_{4}-\mathrm{N}$, and $\mathbf{a}_{D}$ is the denitrification rate $[\mathrm{m} / \mathrm{d}]$.

\section{Kinetics for $\mathrm{NH}_{4}-\mathbf{N}(\boldsymbol{H})$}

Variation of $\mathrm{NH}_{4}-\mathrm{N}$ per unit volume and unit time is derived by totaling the $\mathrm{NH}_{4}-\mathrm{N}$ amount brought into inner body of the pond via inflow load, with influx of $\mathrm{NO}_{\mathrm{x}}-\mathrm{N}$ by rainfall, and with concentration of $N$ accumulating through the mineralization process and elution of $N$ from bottom mud. However, some $\mathrm{NH}_{4}-\mathrm{N}$ amount is lost through outflow discharge from the inner side of the pond, and also $N$ is taken away during the nitrification and phytoplankton processes.

$$
\frac{d H}{d t}=\frac{q_{\text {in }}}{V} H_{\text {in }}+\frac{q_{R}}{V} H_{R}-\frac{q_{\text {out }}}{V} H-\mathbf{a}_{N} H-\left(1-r_{1}\right) \mu_{N} O
$$

$$
+\mathbf{a}_{M} O+\frac{E_{H}}{h}
$$

where $\mathbf{a}_{M}$ is the mineralization rate of Org-N to $\mathrm{NH}_{4}-\mathrm{N}$ $\left[\mathrm{d}^{-1}\right]$, and $E_{H}$ is the elution rate of $N$ from bottom mud $\left[\mathrm{g} /\left(\mathrm{m}^{2} \square \mathrm{d}\right)\right]$.

\section{Kinetics for Org-N $(O)$}

Variation of Org-N per unit volume and unit time is added in through the inflow load, influx of $\mathrm{NO}_{\mathrm{x}}-\mathrm{N}$ by rainfall, and amount of $N$ derived from anabolism by photosynthesis of the phytoplankton and mineralization process. But there is also some loss of Org-N via outflow from inside the system and phytoplankton process.

$$
\frac{d O}{d t}=\frac{q_{\text {in }}}{V} O_{\text {in }}+\frac{q_{R}}{V} O_{R}-\frac{q_{\text {out }}}{V} O+\mu_{N} O-\mathbf{a}_{M} O-\mathbf{a}_{S} \frac{O}{h}
$$

where $\boldsymbol{a}_{S}$ is the settling velocity of Org-N (detritus/phytoplankton) $[\mathrm{m} / \mathrm{d}]$. The intake of $N$ by phytoplankton is the process of anabolism by photosynthesis of phytoplankton, and it is the summation between the intake of $\mathrm{NO}_{\mathrm{x}}-\mathrm{N}$ by phytoplankton and the intake of $\mathrm{NH}_{4}-\mathrm{N}$ by phytoplankton.

\section{Kinetics for $\mathrm{PO}_{4}-\mathrm{P}(\boldsymbol{P})$}

Variation of $\mathrm{PO}_{4}-\mathrm{P}$ per unit volume and unit time is brought in via inflow load to the pond, influx of $\mathrm{NO}_{\mathrm{x}}-\mathrm{N}$ by rainfall, and together with the amount of $\mathrm{P}$ absorbed during the mineralization process. Nevertheless, some $\mathrm{PO}_{4}-\mathrm{P}$ is transported out through outflow from the pond, phytoplankton, and some $P$ is lost within the elution period.

$$
\frac{\mathrm{d} P}{\mathrm{~d} t}=\frac{q_{\text {in }}}{V} P_{\text {in }}+\frac{q_{R}}{V} P_{R}-\frac{q_{\text {out }}}{V} P+\beta_{M} Y-\mu_{P} Y+\frac{E_{P}}{h}
$$

where $\beta_{M}$ is the mineralization rate of Org- $\mathrm{P}$ to $\mathrm{PO}_{4}-\mathrm{P}$ $\left[\mathrm{d}^{-1}\right], \mu_{P}$ is the intake rate of $P$ by phytoplankton $\left[\mathrm{d}^{-1}\right]$, and $E_{P}$ is the elution rate of $P$ from bottom mud $\left[\mathrm{g} /\left(\mathrm{m}^{2} \square \mathrm{d}\right)\right]$.

\section{Kinetics for Org-P $(\boldsymbol{Y})$}

Variation of Org-P per unit volume and unit time is transported in through inflow to inside the system of the 
pond, influx of $\mathrm{NO}_{\mathrm{x}}-\mathrm{N}$ by rainfall, and added amount of $P$ via anabolism by photosynthesis of phytoplankton. At the same time, some Org-P variation is lost through outflow volume from the pond system, and the mineralization and detritus/phytoplankton processes.

$$
\frac{d Y}{d t}=\frac{q_{\text {in }}}{V} Y_{\text {in }}+\frac{q_{R}}{V} Y_{R}-\frac{q_{\text {out }}}{V} Y-\beta_{M} Y+\mu_{P} Y-\beta_{S} \frac{Y}{h}
$$

where $\beta_{S}\left(=\mathbf{a}_{S}\right)$ is the settling velocity of Org-P (detritus/phytoplankton) [m/d]. The anabolism by photosynthesis of phytoplankton is exactly the intake of $\mathrm{PO}_{4}-\mathrm{P}$ by phytoplankton.

\section{Set of model parameters}

1) Nitrification rate:

$$
\mathbf{a}_{N}=0.1 \mathrm{~d}^{-1}
$$

2) Intake rate of N/P by phytoplankton

$$
\begin{aligned}
& \mu_{N}=\mu_{P}=\max \left(\mu_{1}, \mu_{2}\right), \mu_{1}=\mu_{\max } \frac{\bar{N}+\bar{H}}{k_{N}+(\bar{N}+\bar{H})}, \\
& \mu_{2}=\mu_{\max } \frac{\bar{P}}{k_{P}+\bar{P}}
\end{aligned}
$$

where $\mu_{\max }\left[\mathrm{d}^{-1}\right]$ is the maximum specific growth rate and is determined by referring to previous literature or by conducting trial-and-error optimizations, $k_{N}(=0.1 \mathrm{mg} / \mathrm{L})$ and $k_{P}(=0.01 \mathrm{mg} / \mathrm{L})$ denote half-saturation constants for $N$ and $P$, respectively, $\bar{P}$ and $\bar{N}$, and $\bar{H}$ denote, respectively, average values of $\mathrm{PO}_{4}-\mathrm{P}, \mathrm{NO}_{\mathrm{X}}-\mathrm{N}$ and $\mathrm{NH}_{4}-\mathrm{N}$ in the observed period.

3) Distribution constant to $\mathrm{NO}_{\mathrm{X}}-\mathrm{N}$ and $\mathrm{NH}_{4}-\mathrm{N}$ :

$$
r_{1}=\frac{\bar{N}}{\bar{N}+\bar{H}}
$$

4) Denitrification rate:

$$
\mathbf{a}_{D}=0.012 \mathrm{~m} / \mathrm{d} \text {. }
$$

5) Elution rate of N/P from bottom mud

Rainfall $(\mathrm{mm} / \mathrm{d})$
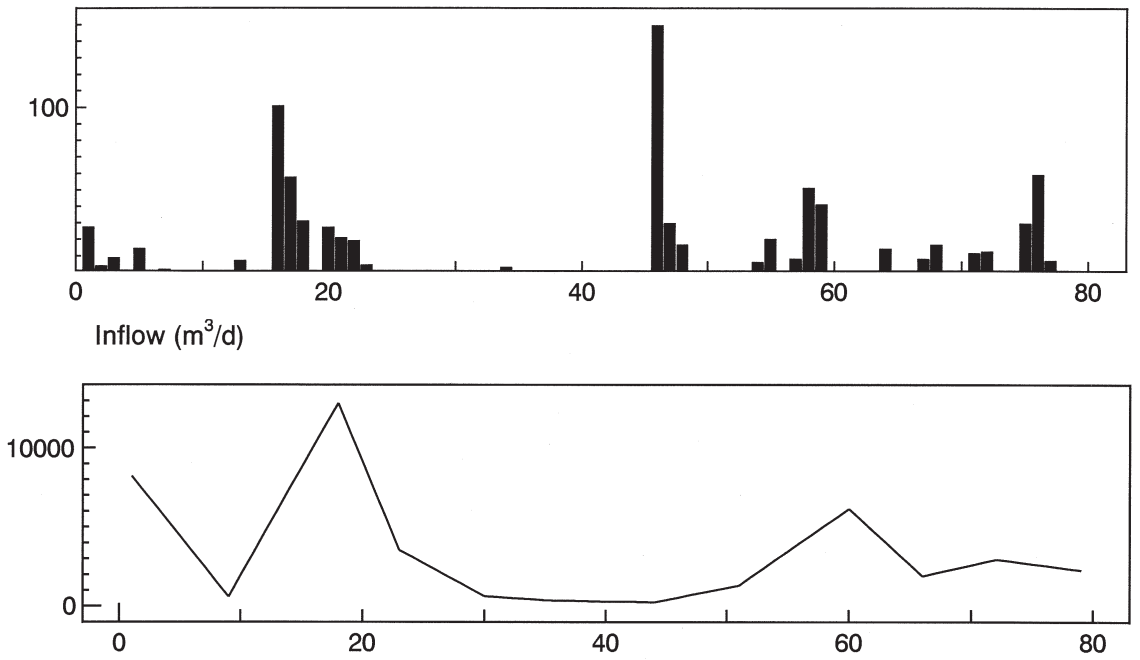

$\mathrm{TN}(\mathrm{mg} / \mathrm{l})$

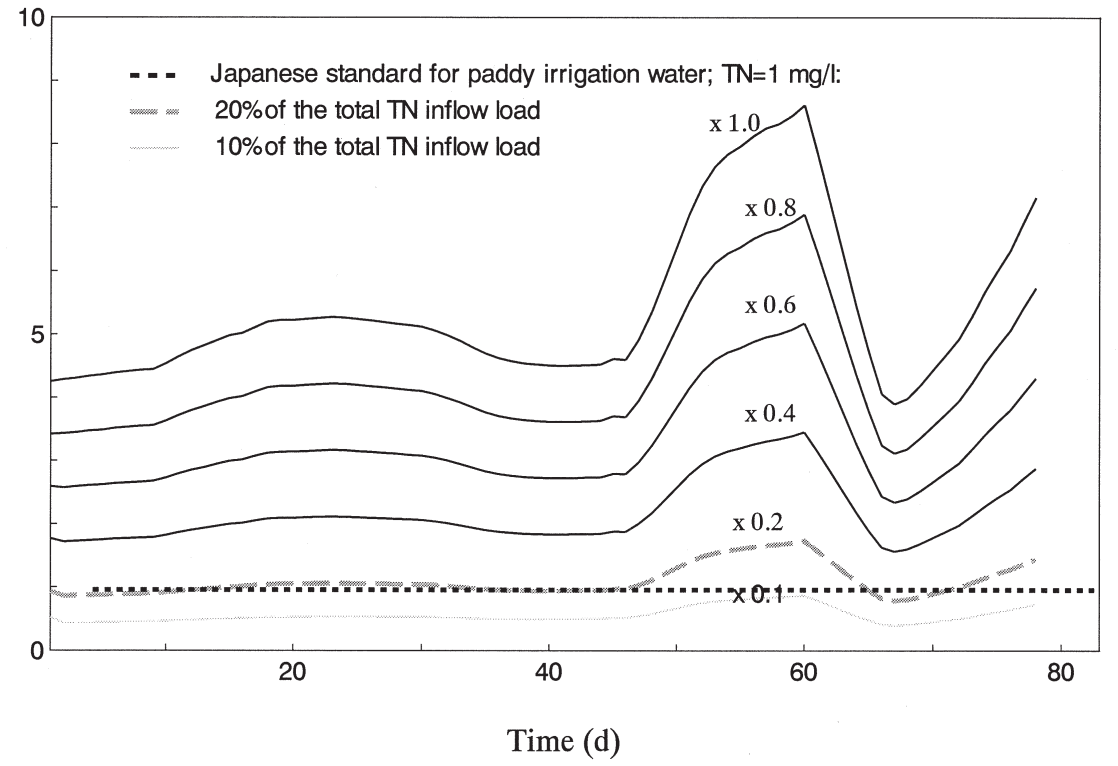

Fig. 4. Results of scenario analysis. 
The parameters of $E_{H}$ and $E_{P}$ are determined by an elution test or by referring to previous literature.

6) Mineralization rate of Org-N/Org-P:

The parameters of $\mathbf{\alpha}_{M}$ and $\boldsymbol{\beta}_{M}$ are determined by referring to previous literature or by conducting trialand-error optimizations.

7) Settling velocity of N/P (detritus/phytoplankton):

The parameter of $\boldsymbol{\beta}_{s}\left(=\mathbf{\alpha}_{s}\right)$ is determined by referring to previous literature or by conducting trial-anderror optimizations.

A time series of nitrogen and phosphorus in the pond can be acquired by solving the formulae of (1) to (5), and the Runge-Kutta-Gill method is applied to the numerical solution of the ordinary differential equations.

\subsection{Scenario Analysis}

According to the observation by Saitoh et al. (2006), the concentrations of TN and TP in the pond were fluctuating closely related to ones of inflow. It would be considered that inflow load directly causes rich nutrient salts in the pond. Therefore, the reduction of inflow load seems to be the most effective approach in order to fulfill the Japanese water quality standard of TN for paddy rice and to suppress the progress of eutrophication. In order to acquire supporting data for the water environmental conservation, the scenario analyses are conducted under the assumption that the inflow load of TN and TP via inflow water is 80\%, 60\%, 40\%, 20\%, and finally $10 \%$ of the current situation.
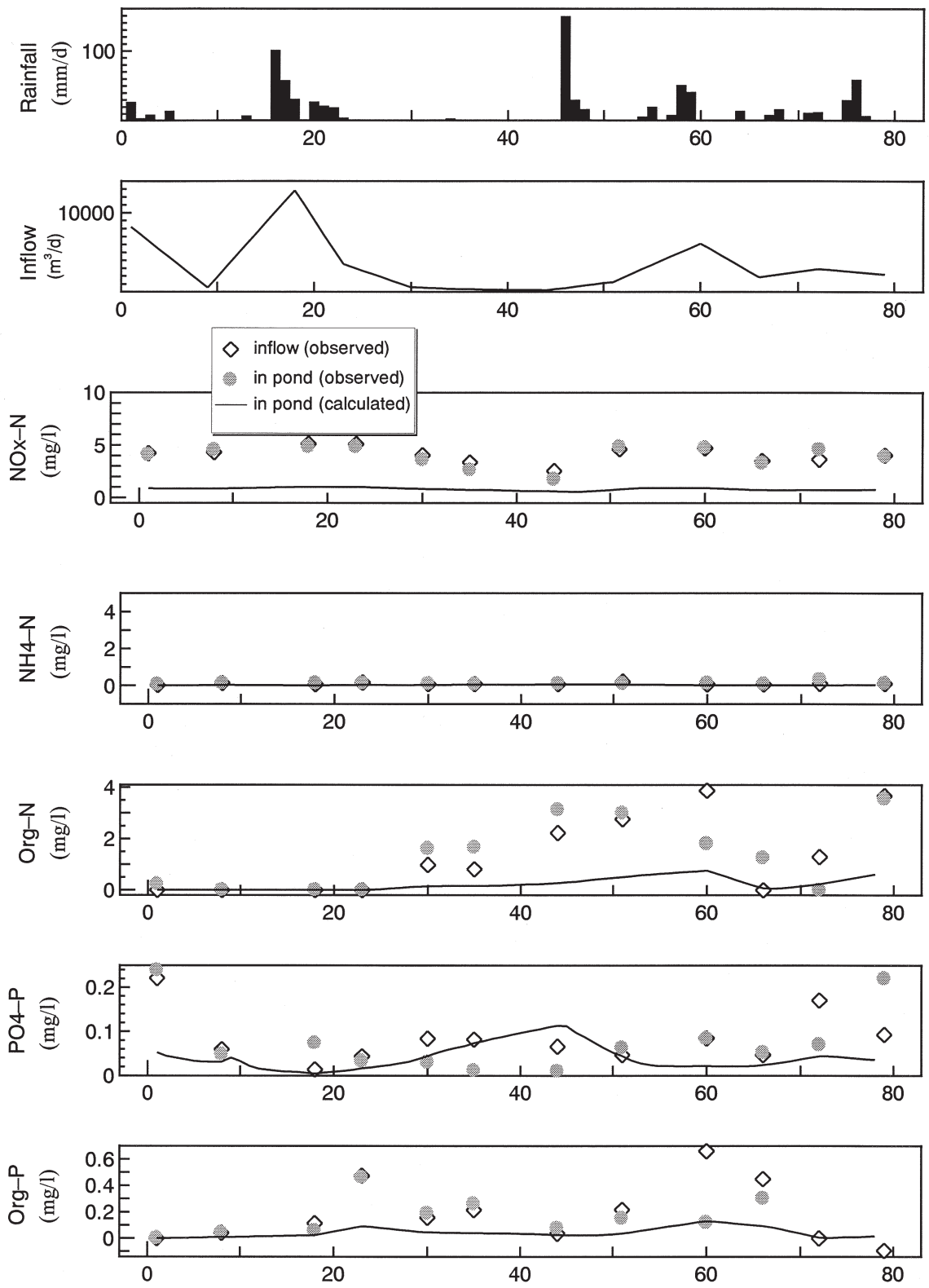

Time (d)

Fig. 5. Simulated results of $80 \%$ reduction of inflow load. 


\section{RESULTS AND DISCUSSION}

The observed data of sample water and the calculation results of 5 different formations in nitrogen and phosphorus are compared in Fig. 2. The graph clearly shows that regardless of rainfall volume changes, the calculated results of 5 indices of $\mathrm{NO}_{\mathrm{x}}-\mathrm{N}, \mathrm{NH}_{4}-\mathrm{N}$, Org- $\mathrm{N}$, $\mathrm{PO}_{4}-\mathrm{N}$ and Org-P present very close values of the ones observed. This result means that the ecosystem model used in this research could not only reproduce the matter cycle for nitrogen and phosphorus in Toishigawara pond but could also be sufficiently applied to evaluate and predict variations of other water quality items for the conservation and improvement projects of water environment.

Referring to the results, TN (which is the summation of $\mathrm{NO}_{\mathrm{x}}-\mathrm{N}, \mathrm{NH}_{4}-\mathrm{N}$, and Org-N) is relatively high, around $4.0 \mathrm{mg} / \mathrm{L}$ found in the pond. Meanwhile, TP of $\mathrm{PO}_{4}-\mathrm{P}$ and Org-P is also high in both inflow load and pond water. TN concentration is increasing significantly with the increment of inflow water, which means that inflow water is the main factor of TN accumulation.

With regard to the scenario analysis discussed earlier, 80\% reduction of total nitrogen and total phosphorus transported into the pond through inflow source has been studied and visualized clearly in Fig. 4. In this study, if only $20 \%$ of the TN amount is loaded into the pond, the average concentration of $\mathrm{TN}$ in the pond will be reduced as low as the Japanese water quality standard of irrigation water for TN (less than $1 \mathrm{mg} / \mathrm{L}$ ). The simulated results of 20\% inflow load are shown in Fig. 5. In the meantime, the concentration of TP in the forms of $\mathrm{PO}_{4}-\mathrm{P}$ and Org-P is remarkably declining as well. Therefore, $80 \%$ reduction of $\mathrm{TN}$ in the inflow water load should be the best solution for standard irrigation water in Japan.

\section{CONCLUSION}

The time series approach with the ecosystem model is found to be very useful in addition to the experimental practices of water sampling. Some significant procedures have been successfully performed through this study. Initially, a mathematical model of the pond ecosystem has been developed for predicting the concentration of water quality indices $\mathrm{TN}$ and $\mathrm{TP}$ in Toishigawara agricultural pond. A comparison between the calculated results and the observed data of water sampling experiments in the laboratory has also been carried out to detect the differences and the accuracy of the developed model. Consequently, a scenario analysis assuming $80 \%$ reduction of the inflow load has been critically studied and concluded. This is the most satisfactory assumption for this study in order to stabilize the variation of total nitrogen and total phosphorus loading into the pond in order to protect water quality and to meet the demand for agricultural irrigation water.

\section{REFERENCES}

Chapra, S. C. 1997 Surface Water Quality Modeling, WCB McGraw-Hill, 521-663

Cheng, X. and S. Li 2006 An analysis on the evolvement processes of lake eutrophication and their characteristics of the typical lakes in the middle and lower reaches of Yangtze River, Chinese Science Bulletin, 51: 1603-1613

Davie, T. 2002 Fundamentals of Hydrology, Taylor \& Francis Group, 106-129

Kato, T. 2005(a) Simulation of water quality with the application of system dynamics model for population and land-use changes, Paddy Water Environ, 3: 103-109

Kato, T. 2005(b) Development of water quality tank model classified by land use for nitrogen load reduction scenarios, Paddy Water Environ, 3: 21-27

Qin, B., L. Yang, F. Chen, G. Zhu, L. Zhang and Y. Chen 2006 Mechanism and control of lake eutrophication, Science in China Press, 51: 2401-2412

Saitoh, T., M. Harada, K. Hiramatsu, M. Mori (2006) Numerical Study on Nitrogen Dynamics and Scenario Analysis for Reducing Nitrogen in an Agriculture Pond using an Ecosystem Model, Sci. Bull. Fac. Agr., Kyushu Univ., 61, 2: 297-301 (in Japanese with summary in English)

Schwarz, D., R. Grosch, W. Gross and S. Hoffmann-Hergarten 2005 Water quality assessment of different reservoir types in relation to nutrient solution use in hydroponics, Agricultural Water Management, 71, 2:145-166

Wetzel, R. G. 2001 Limnology, Lake and River Ecosystems, ELSEVIER ACADEMIC PRESS, 93-150

Zheng, L., C. Chen and F. Y. Zhang 2004 Development of Water quality model in the Sattila River Estuary, Georga, Ecological Modelling, 178: 3-4 